\title{
Molecular Detection of Toxoplasma gondii Oocytes in the Soil from the Public Parks of the Arak City, Iran
}

\author{
Hadis Solymane ${ }^{1}$, Zahra Eslamirad ${ }^{2 *}$, Mansour Bayat ${ }^{3}$, Reza Hajihossein ${ }^{4}$ \\ ${ }^{1}$ Department of Microbiology, Islamic Azad University, Science and Research Branch, Tehran, Iran. \\ ${ }^{2}$ Departments of Parasitology, School of Medicine, Arak University of Medical Sciences, Arak, Markazi, Iran. \\ ${ }^{3}$ Department of Medical and Veterinary Mycology, Faculty of Specialized Veterinary Sciences, Islamic Azad University, Science and Research. \\ Branch, Tehran, Iran. \\ ${ }^{4}$ Department of Parasitology, School of Medicine, Arak University of Medical Sciences, Arak, Markazi, Iran.
}

\author{
Received: 25 Nov 2013 \\ Revised: 27 Dec 2013 \\ Accepted: 17 Jan 2014 \\ Corresponding Author: \\ Zahra Eslamirad \\ Departments of Parasitology, School \\ of Medicine, Arak University of \\ Medical Sciences, Arak, Markazi, \\ Iran. \\ Phone: +98-86 34173525 \\ E-mail: dr.eslami@arakmu.ac.ir
}

\begin{abstract}
Background: Soil structure is mainly composed of sand, silt, clay, and organic materials. Organisms can live in the soil. The large number of stray cats in the cities of Iran is a major environmental and health problem. Toxoplasma oocysts are shed with the feces of cats, so soil is known as a potential source of transmission of toxoplasmosis. The aim of this study was to determine the soil contamination with Toxoplasma gondii oocyst in the public parks of the Arak city. Materials and Methods: Sixty soil samples were collected from 15 main parks of Arak city. Four soil samples from the children's playground, a potting place, around trash bins, and around toilets were taken. Oocyst was isolated from soil by floatation in saturated sucrose. Floating debris was tested by two methods: staining by the modified Ziehl-Neelsen technique and PCR. The target of PCR was the $122 \mathrm{bp}$ fragment of the $\mathrm{B} 1$ gene.

Results: From 60 soil samples of public parks of Arak city, 8 samples (13\%) were suspected to Toxoplasma oocyst contamination in staining smears. Only 3 samples (5\%) of 60 samples were positive in PCR. The results showed that the staining method is not a good method to detect oocysts in the soil because the diversity of oocyst in soil is very high and similar in appearance.

Conclusion: This study showed soils of public parks in the Arak city were contaminated to oocyst of Toxoplasma. Also molecular method for the detection of parasites in the soil was more suitable than staining method.
\end{abstract}

Keywords: Oocyst; PCR; Soil; Toxoplasma gondii

Please cite this article as: Solymane H, Eslamirad Z, Bayat M, Hajihossein R. Molecular Detection of Toxoplasma gondii Oocytes in the Soil from the Public Parks of the Arak City, Iran. Res Mol Med. 2014; 2 (1): 35-38

\section{Introduction}

Soil structure is mainly composed of sand, silt, clay and organic materials. Organisms can live in the soil. Because soil structure can provides the possibility of life for many of the microorganisms. The soil looks a great reservoir of pathogenic and non-pathogenic microorganisms, and is a potential source of spread (1).

Soil has a role in the spread of Toxoplasma gondii. This parasite can infect most warm-blooded vertebrates, and its prevalence is high (2). It is estimated that about $15 \%$ to $85 \%$ of the world's population are chronically infected (3). Toxoplasma gondii can cause miscarriage in pregnant women and severe disorders in neonates (4). Part of evolution of its done in the soil. Disposal of cat feces in the environment is causing soil pollution. Study of soil contamination with Toxoplasma gondii can help to understand transmission patterns in different parts of the world (5).

Researchers such as Du, Lass and Tavalla found evidence that soil contaminated with Toxoplasma oocytes may play an important role in the epidemiology and transmission of human toxoplasmosis (2, 6-7). In addition, their studies showed that conventional PCR detection of $T$. gondii oocysts in the soil (2, 6-7). Afonso et al. showed that high concentrations of oocysts can be found in soil samples using molecular 
methods (8). Due to the large number of stray cats in various local of towns, prevalence of zoonotic diseases has increased. Now a lot of street cats are seen in different parts of the Arak city. These cats dispose of feces in the soil in various places such as in public parks. It seems that soil contamination at the park, is causing further spread of the toxoplasmosis disease in urban communities especially in children. Therefore the aim of this study was to determine the extent of soil contamination in the public parks of the Arak city with $T$. gondii oocyst was done. In this study, two methods were used, the microscopic observation of stained smear of soil samples and molecular method.

\section{Materials and Methods}

Sixty soil samples were collected from 15 main parks of Arak city (from April to June 2013). Four soil samples from the children's playground, a potting place, around trash bins and around toilets were taken. Approximately $500 \mathrm{~g}$ of soil to a depth of $3 \mathrm{~cm}$ were collected from each site and transported to the laboratory in clean bags. Soil samples were dried at Laboratory. Samples were kept in suitable place until experiment. Oocyst was isolated from soil by floatation in saturated sucrose, as described previously (9). The floating debris was staining by the modified Ziehl-Neelsen technique (10).

Table 1. Detection of Toxoplasma oocyst in the soil of Arak city in separate of sampling place and experiment method

\begin{tabular}{lccc}
\hline & Children's playground & Potting place & Around trash bins \\
\hline $\begin{array}{l}\text { Microscopic observation of } \\
\text { stained smear }\end{array}$ & 3 & 5 & 0 \\
$\begin{array}{l}\text { Molecular method } \\
\text { Around toilets }\end{array}$ & 1 & 2 & 0 \\
\hline
\end{tabular}

The DNA for PCR was extracted by the conventional method. Briefly, the floating debris was suspended in 100 micro liter TE buffer $(10 \mathrm{mM}$ Tris- $\mathrm{HCl}, 1 \mathrm{mM}$ EDTA-2Na; $\mathrm{pH}$ 8.0) containing $1.5 \%$ SDS, and allowed to stand at room temperature for at least 3 hours. DNA was extracted by an equal volume of phenol-chloroform solution, precipitated by isopropyl alcohol at $-20{ }^{\circ} \mathrm{C}$, washed with $80 \%$ ethanol and finally the pellet was dried. The dried pellet, dissolved in 15 of sterile distilled water, was used for the PCR.

The target of PCR was the $122 \mathrm{bp}$ fragment of the highly conserved 35 fold repetitive $\mathrm{B} 1$ gene (AF179871). PCR reaction was performed by a pair of primer (11):

Forward: 5' AAC GGG CGA GTA GCA CCT GAG GAG A 3"

Revers: 5' TGG GTC TAC GTC GAT GGC ATG ACA AC 3

In this study Master-Mix kit (CinnaGen Co., Iran) was used. For remove the inhibitors of soil DNA, 10 $\mu \mathrm{M}$ of bovine serum albumin (BSA) was added to PCR reaction (9).

The final reaction volume was $25 \mu \mathrm{l}$. The amplification was performed by $5 \mathrm{~min}$ at $94^{\circ} \mathrm{C}$ initial step, followed by 35 cycles: denaturation for 30 second at $95{ }^{\circ} \mathrm{C}$, annealing for 30 second at $58^{\circ} \mathrm{C}$ and extension for 30 second at $72^{\circ} \mathrm{C}$. PCR products were analyzed by electrophoresis on $1.5 \%$ agarose gel and stained with safe stain.

\section{Results}

From 60 soil samples that examined by staining technique, 8 samples (13\%) were suspected to be contaminated with Toxoplasma. Three positive samples from children's playground and five of them from potting place were got. The positive samples were collected from 8 different parks.

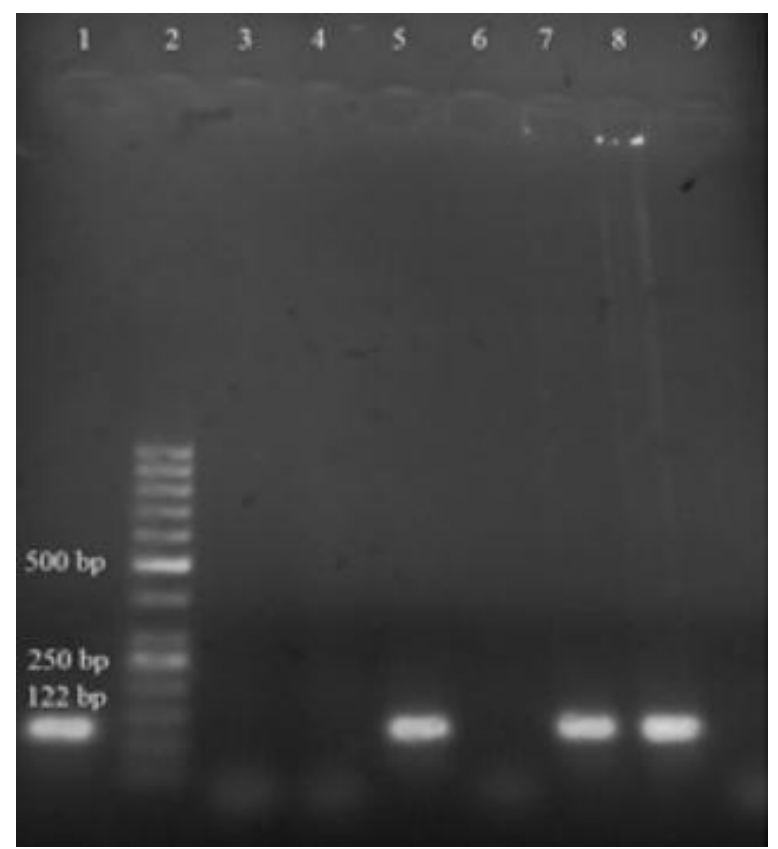

Figure 1. PCR products of soil samples on agarose $1 \%$. Lane1, Positive control; Lane2, molecular weight marker 50 bp; Lane3, negative control; Lanes 5, 7, 8 positive soil samples; Lanes 4, 6, 9 negative soil samples

From 60 soil samples that examined by PCR, 3 samples $(5 \%)$ were positive. One positive sample from children's playground and two of them from potting place were got. In other words, molecular 
methods confirmed the results of staining in 3 cases(Table1). The $122 \mathrm{bp}$ fragment was amplified in 3 samples that were positive by PCR (Figure 1).

In soil samples were stained with Ziehl-Neelsen method objects like oocyst were observed (Figure 2). But differentiation of Toxoplasma oocysts and others like Cryptosporidium oocysts was problem.

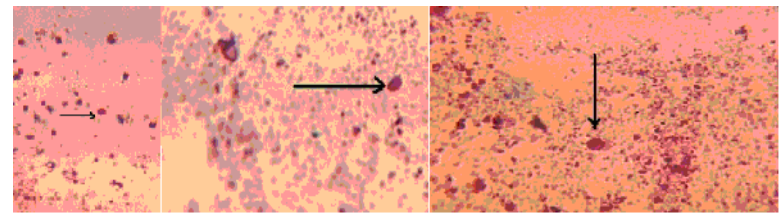

Figure 2. Oocyst-like objects are shown in soil smears. These objects are shown with arrows.

\section{Discussion}

The present study was carried out to determine the extent of soil contamination in the public parks of the Arak city with $T$. gondii oocyst. From 60 soil samples of public parks of Arak city, 8 samples (13\%) were suspected to Toxoplasma oocyst contamination in staining smear. Only 3 samples (5\%) of 60 samples were positive in PCR. Cat plays a role in the spread of zoonotic diseases. Toxoplasmosis is one of the most important diseases. We know, part of the evolution of Toxoplasma is done in intestine of cat and other part in the soil (13). The large number of cats in the cities of Iran is a major environmental and health problem. In this regards Arak city is not an exception. Toxoplasma oocysts are shed with the feces of cats, so soil is known as a potential source of transmission of toxoplasmosis. There is a little study about contamination of soil to oocyst of Toxoplasma gondii. Ruiz (1973) isolated oocyst of Toxoplasma from soi (14). Frenkel et al. (1975) studied survival time of Toxoplasma oocysts in the soil (5). Kuczynska indicate that the $\mathrm{NaCl}$ flotation method is suitable for routine detection of oocysts from soils (15). Lass et al. detected Toxoplasma gondii oocysts in environmental soil samples using molecular methods (2). Du et al. evaluated the relationship between soil contamination status of Toxoplasma gondii oocysts and Toxoplasmosis infection in pigs in 12 pig farms with different density of cats in central China. The results indicated that a high seroprevalence of $T$. gondii in pigs was found in the pig farms with high soil contamination by $T$. gondii oocysts (16). And also Du studied on the contamination of Toxoplasma gondii oocysts in the soil of public parks of Wuhan, China. The results indicated that the soil of public parks contaminated with $T$. gondii oocysts may play a role in the epidemiology of toxoplasmosis and effective preventive measures should be considered. Moreover, the conventional PCR used in his study is applicable to detect $T$. gondii oocysts in soil samples (7).

Tavalla et al. determined the prevalence of all parasitic forms in soil of public places in Tehran city by using two flotation methods. The results indicated that the sodium nitrate flotation and sucrose flotation method statistically were differed to parasites detection in soil samples (17). And also they reported that $8.7 \%$ of soil samples were contaminated to oocyst of Toxoplasma in Tehran. They used molecular methods for detection of Toxoplasma oocytes but they used commercial genomic mini kit for DNA extraction (6). Different levels of soil contamination in the Tehran and Arak cities are related to the climate and soil characteristics of these areas. But also differences in the DNA extraction procedure could be caused to this regards. It is known that some inhibitors present in the soil. These inhibitors can inhibit PCR reactions. Commercial kits for DNA extraction can remove soil inhibitors.

We were expected to find oocysts of Toxoplasma around the trash bins but all experiments were negative. According to Afonso's results, our findings are justified. Afonso et al. showed that spatial distribution of contamination soil with oocyst of Toxoplasma is highly heterogeneous. Positive samples were only found in some of the cats' defecation sites (8).

Toxopalsma oocyst has a resistant wall consisted of several layers, which causes difficult DNA extraction (18). Therefore it is possible that in our molecular study, soil contamination with $T$. gondii oocyst is greater than our present.

Our study is the only study in which the staining was used to detect oocysts in the soil. The results showed that the Ziehl-Neelsen staining is not a good method to detect oocysts in the soil. Because all particles in the soil are the same color and they are not reliable microscopic study. Molecular methods for the detection of parasites in the soil are more suitable.

\section{Conclusions}

Finally, this study showed soil of public parks in the Arak city are contaminate to oocyst of Toxoplasma gondii and may play a role in the epidemiology of toxoplasmosis in Arak city. Also molecular method for the detection of parasites in the soil was more suitable than staining method.

\section{Acknowledgments}

Authors are grateful to research laboratory personnel's of Arak University of Medical Sciences for providing the necessary facilities to carry out this work. 


\section{References}

1. Dabritz HA, Conrad PA. Cats and Toxoplasma: implications for public health. Zoonoses Public Health. 2010; 57 (1): 34-52. PMID: 19744306

2. Lass A, Pietkiewicz H, Modzelewska E, Dumètre A, Szostakowska $\mathrm{B}$, Myjak P. The first detection of Toxoplasma gondii DNA in environmental fruits and vegetables samples. Eur J Clin Microbiol Infect Dis. 2012; 31(6):1101-8. PMID: 21948336

3. Pappas G, Roussos N, Falagas ME. Toxoplasmosis snapshots: Global status of Toxoplasma gondii seroprevalence and implications for pregnancy and congenital toxoplasmosis. Int J Parasitol. 2009; 39 (12): 1385-94. PMID: 19433092

4. Remington JS, McLeod R, Thulliez P, Desmonts G. Infectious Diseases of the Fetus and Newborn Infant (Sixth Edition). Philadelphia: W.B. Saunders; 2006. p. 947-1091.

5. Frenkel JK, Ruiz A, Chinchilla M. Soil survival of Toxoplasma oocyst in Kansas and Costa Rica. Am J Trop Med Hyg. 1975; 24(3): 439. PMID: 1098494

6. Tavalla M, Oormazdi H, Akhlaghi L, Shojaee S, Razmjou E, Hadighi R, et al. Genotyping of Toxoplasma gondii Isolates from Soil Samples in Tehran, Iran. Iranian Journal of Parasitology 2013; 8 (2): 227-33. PMID: 23914235

7. Du F, Feng HL, Nie H, Tu P, Zhang QL, Hu M, et al. Survey on the contamination of Toxoplasma gondii oocysts in the soil of public parks of Wuhan, China. Vet Parasitol. 2012; 184(2-4): 1416. PMID: 21906882

8. Afonso E, Lemoine M, Poulle M-L, Ravat M-C, Romand S, Thulliez P, et al. Spatial distribution of soil contamination by Toxoplasma gondii in relation to cat defecation behaviour in an urban area. Int J Parasitol. 2008; 38(8-9): 1017-23. PMID: 18325523

9. Matsuo J, Kimura D, Rai SK, Uga S. Detection of Toxoplasma oocysts from soil by modified sucrose flotation and PCR methods. Southeast Asian J Trop Med Public Health. 2004; 35 (2): 270-4. PMID: 15691123
10. Clarke SC, McIntyre M. Modified detergent Ziehl-Neelsen technique for the staining of Cyclospora cayetanensis. J Clin Pathol. 1996; 49(6):511-2. PMID: 8763270

11. Sambrook J, Fritsch EF, Maniatis T. Molecular cloning: a laboratory manual, 2nd edn. Cold Spring Laboratory Press. New York. 1989

12. Nagy B, Bán Z, Beke A, Nagy GR, Lázár L, Papp C, et al. Detection of Toxoplasma gondii from amniotic fluid, a comparison of four different molecular biological methods. Clinica Chimica Acta 2006; 368 (1-2): 131-7.

13. Dubey JP. The history and life cycle of Toxoplasma gondii. Toxoplasma gondii. 2007. 1:1-7

14. Ruiz A, Frenkel J, Cerdas L. Isolation of Toxoplasma from soil. Parasitol Res. 2009; 105(1):17-24. PMID: 19418068

15. Kuczynska E, Shelton DR. Method for detection and enumeration of Cryptosporidium parvum oocysts in feces, manures, and soils. Appl Environ Microbiol. 1999; 65(7):2820-6. PMID: 10388670.

16. Du F, Zhang Q, Yu Q, Hu M, Zhou Y, Zhao J. Soil contamination of Toxoplasma gondii oocysts in pig farms in central China. Vet Parasitol. 2012; 187 (1-2): 53-6. PMID: 22265079

17. Tavalla M, Oormazdi H, Akhlaghi L, Razmjou E, Moradi Lakeh M, Shojaee S, et al. Prevalence of parasites in soil samples in Tehran public places. Afr J Biotechnol. 2012; 11 (20): 4575-8.

18. Lélu M, Gilot-Fromont E, Aubert D, Richaume A, Afonso E, Dupuis E, et al. Development of a sensitive method for Toxoplasma gondii oocyst extraction in soil. Vet Parasitol. 2011; 183 (1-2): 59-67. PMID: 21764217 